disease progression. Arch Dermatol 2003;139:857-66.

5 Agar NS, Wedgeworth E, Crichton S et al. Survival outcomes and prognostic factors in mycosis fungoides/Sézary syndrome: validation of the revised International Society for Cutaneous Lymphomas/ European Organisation for Research and Treatment of Cancer staging proposal. J Clin Oncol 2010;28:4730-9.

6 Benton EC, Crichton S, Agar NS et al. Cutaneous Lymphoma International Prognostic Index (CLIPI). Br J Dermatol 2010;163 (Suppl 1):8-11.

7 Kaye FJ, Bunn PA Jr, Steinberg SM et al. A randomized trial comparing combination electron-beam radiation and chemotherapy with topical therapy in the initial treatment of mycosis fungoides. N Engl J Med 1989; 321:1784-90.

8 Scarisbrick JJ, Taylor P, Holtick U et al. U.K. consensus statement on the use of extracorporeal photopheresis for treatment of cutaneous T-cell lymphoma and chronic graft-versus-host disease. $\mathrm{Br} J$ Dermatol 2008;158:659-78.

9 Duvic M, Donato M, Dabaja B et al. Total skin electron beam and non-myeloablative allogeneic hematopoietic stem-cell transplantation in advanced mycosis fungoides and Sézary syndrome. J Clin Oncol 2010;28:2365-72.

Address for correspondence:

Dr C Duhovic, Clinical Fellow in Dermatology, St John's Institute of Dermatology, St Thomas' Hospital, Lambeth Palace Road, London SE1 7EH.

Email: chris_duhovic@hotmail.com

\section{The urticarias: pathophysiology and management}

Clive Grattan, consultant dermatologist, St John's Institute of Dermatology, Guy's and St Thomas' Hospitals NHS Foundation Trust \& Norfolk and Norwich University Hospital

Urticaria has been recognised as an illness since the time of Hippocrates. It is a common disease with an estimated lifetime prevalence of $20 \% .^{1}$ The term is derived from the stinging nettle, Urtica dioica. Indeed, the lay term for urticaria is nettle rash. At one end of the clinical spectrum, urticaria can be brief, mild and no more than a nuisance. When severe, acute urticaria may merge with life-threatening anaphylaxis. Chronic urticaria may cause severe quality of life impairment comparable to ischaemic heart disease. ${ }^{2}$

There has been recent debate about the terminology and classification of the disease. In the latest European consensus on urticaria, ${ }^{3}$ it is defined as a heterogeneous group of diseases (ie the urticarias) rather than a single entity. The semantics are unimportant but reflect the recognition that there are distinct clinical patterns with more than one aetiology.

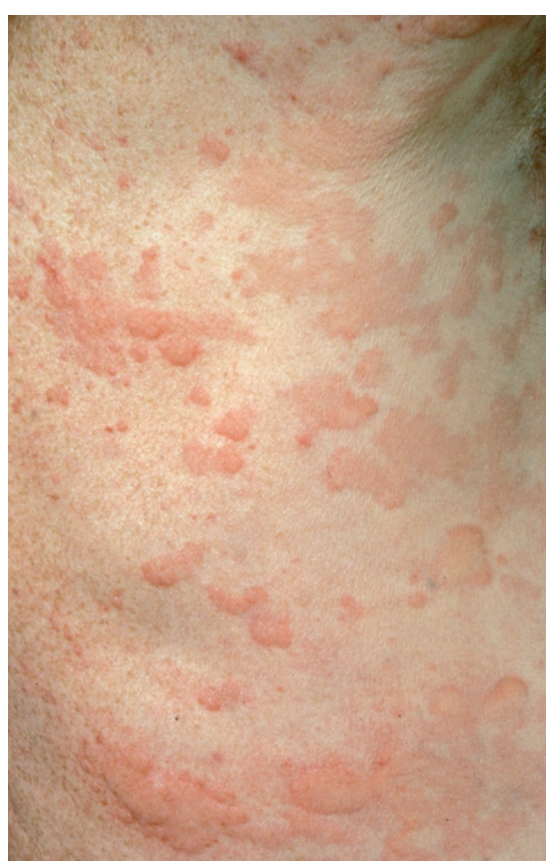

Fig 1. Wheals are superficial swellings with pale centres surrounded initially by a red flare that flatten and become as singular before fading.

\section{Definition}

The urticarias are characterised by shortlived, superficial, itchy pale swellings with a surrounding red flare (Fig1) that become pink and flatten as they resolve over hours (wheals), and/or deep pale swellings of the subcutis and submucosa that may be painful rather than itchy and last longer (angio-oedema) (Fig 2). Collectively, urticaria presents with wheals, angio-oedema or both.

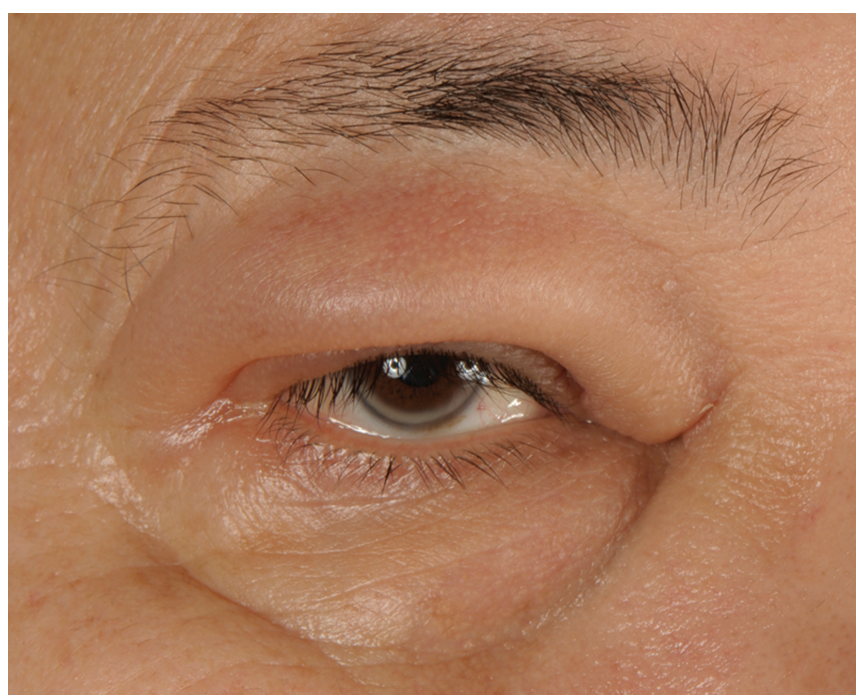

Fig 2. Angiooedema of the upper eyelid showing a deep swelling without change of skin colour. 


\section{Classification (Table 1)}

Urticaria has historically been divided into acute and chronic disease, dependent on continuous disease duration. This is somewhat useful in that acute urticaria tends to run its course over weeks, may be due to an allergic trigger and usually does not recur if it can be identified and avoided. It is easily the commonest presentation of urticaria and usually happens to young people, although ranges from infancy to old age. Urticaria becomes chronic if disease activity continues for six weeks or longer. In clinical practice, the situation is often not so tidy. Patients present with urticarial activity that may be active for a few weeks, settle for another few weeks or months, then unpredictably return to what it was previously. The term acute or chronic intermittent urticaria can be used to describe this fluctuating activity (depending on the duration of the

\section{Table 1. Classification of the urticarias and differential diagnosis.}

\begin{tabular}{|c|c|}
\hline Urticaria & Classification \\
\hline Spontaneous & $\begin{array}{l}\text { - Acute: }<6 \text { weeks continuous disease activity } \\
\text { - Chronic: } 6 \text { weeks continuous disease activity }\end{array}$ \\
\hline Inducible & \\
\hline Physical & $\begin{array}{l}\text { Mechanical: } \\
\text { - Symptomatic dermographism } \\
\text { - Delayed pressure urticaria } \\
\text { - Vibratory angio-oedema } \\
\text { Thermal: } \\
\text { - Cold contact urticaria } \\
\text { - Heat contact urticaria }\end{array}$ \\
\hline Other & $\begin{array}{l}\text { - Cholinergic urticaria (sweating induced by overheating or stress) } \\
\text { - Exercise-induced anaphylaxis } \\
\text { - Food and exercise-induced anaphylaxis } \\
\text { - Aquagenic urticaria }\end{array}$ \\
\hline Contact & $\begin{array}{l}\text { - Immunological (allergic) } \\
\text { - Non-immunological (non-allergic) }\end{array}$ \\
\hline $\begin{array}{l}\text { Differential diagnos } \\
\text { Urticarial drug rashe } \\
\text { Urticarial vasculitis }\end{array}$ & \\
\hline $\begin{array}{l}\text { Autoinflammatory } \\
\text { syndromes }\end{array}$ & $\begin{array}{l}\text { Acquired: } \\
\text { - Schnitzler's syndrome } \\
\text { - Adult Still's disease } \\
\text { Hereditary: } \\
\text { - cryopyrin-associated periodic syndrome }\end{array}$ \\
\hline
\end{tabular}

episodes). This degree of precision may not be important in the clinic but should be taken into account when defining populations for research studies.

It used to be routine common practice to qualify chronic urticaria as 'idiopathic' when no physical trigger could be identified. However, it has become increasingly accepted that around $30 \%$ of patients who would previously have been labelled 'idiopathic' have functional autoantibodies that release histamine from healthy donor basophils and mast cells in vitro. ${ }^{4}$ The term 'autoimmune urticaria' has been ascribed to this subgroup of patients, ${ }^{5}$ although the concept has not been endorsed by all authorities. Studies are ongoing to define a cluster of clinical, biochemical and immunological criteria that can be used in daily practice to define these patients.

\section{Spontaneous}

The clinical terms 'ordinary' ${ }^{6}$ or 'spontaneous ${ }^{3}$ are now preferred in Europe to describe urticaria by its presentation rather than aetiology, since the latter can be difficult to assign in routine clinical practice. 'Ordinary' refers to the pattern of disease and 'spontaneous' to the unpredictability of the swellings, but both terms can apply to the same group of patients.

\section{Inducible}

Importantly, the group of spontaneous urticaria is different from patients presenting with urticaria induced by an external physical stimulus or agent. These inducible urticarias are usually chronic in their course and have different clinical characteristics to spontaneous urticaria. Even though the trigger can be demonstrated by simple provocation tests, their cause remains unknown.

Spontaneous and inducible urticarias can overlap but urticaria is usually predominantly one form or the other.

\section{Contact}

The third clinical pattern is contact urticaria. It is elicited either by skin or mucosal contact with a substance that induces histamine release by an allergic or non-allergic mechanism, or from injection of vasoactive mediators, including histamine. The nettle sting reaction is a good example of this. Contact urticaria to cosmetics, foods, plants and stings is common but little is written about it since the cause is usually self-evident to patients who do not consult the medical profession. The serious side of allergic contact urticaria is that it can progress to anaphylaxis in highly sensitive subjects (eg latex allergy).

\section{Differential diagnosis}

The noun 'urticaria' describes a disease but the adjective 'urticarial' is used to describe a rash. The latter may be druginduced, vasculitic or one component of 
Key points

Urticaria is a disease characterised by wheals, angioedema or both

Patients may have spontaneous or inducible urticaria; sometimes both

The mast cell plays a central role in most patterns of urticaria by releasing histamine which, in turn, acts on capillaries and cutaneous nerve endings to elicit the characteristic itchy red wheals

Functional autoantibodies against IgE and the high affinity IgE receptor on mast cells and basophils may cause autoimmune urticaria but can not be assayed routinely

The management of urticaria is primarily the avoidance of aggravating or trigger factors and taking $\mathrm{H} 1$ antihistamines.

Antihistamine-resistant cases may require treatment with a variety of second and third line therapies used off licence

KEY WORDS: urticarias, diagnosis, pathogenesis, angio-oedema

a wider systemic illness such as an autoinflammatory syndrome. It is common for articles on urticaria to embrace urticarial eruptions within the spectrum of urticaria because they may appear indistinguishable. The clinician's skill is to be able to distinguish an urticarial illness from urticaria since the pathogenesis, management and prognosis are importantly different.

\section{Pathogenesis}

It is widely accepted that the cutaneous mast cell has a central role in urticaria. There is some evidence that peripheral blood basophils are relevant to the delayed response of spontaneous urticarial wheals, and they provide a useful model for the investigation of mast cell degranulating stimuli in vitro. Although preformed histamine is released from mast cells on degranulation, together with tryptase and some cytokines, the receptors for histamine are on post-capillary venules and C-fibre nerve endings. These become permeable to plasma and signal the sensation of itch in the central nervous system. Lesional skin biopsies show an early, but not immediate, influx of inflammatory cells including neutrophils, eosinophils, basophils and undifferentiated T-cells. ${ }^{7}$ Eosinophils may degranulate mast cells indirectly by release of major basic pro- tein. ${ }^{8}$ A sustained release of histamine from influxed basophils with generation of cysteinyl leukotrienes (LTs) may prolong the wheal response. However, the clinical importance of LTs is not certain since not many patients with chronic spontaneous urticaria show a convincing response to anti-LTs.

The stimulus for mast cell degranulation may be immunological or nonimmunological (Fig 3). Cross-linking of two or more adjacent allergen-specific immunoglobulin (Ig) E molecules bound to the high affinity IgE receptor (Fc $\in \mathrm{RI}$ ) on mast cells or basophils will initiate a series of calcium-dependent intracellular signalling events leading to incomplete degranulation in allergic urticaria. Autoantibodies against IgE, ${ }^{9}$ Fc $\in \mathrm{RI}^{10}$ or both on basophils and mast cells ${ }^{11}$ cause histamine release in vitro and are thought to underpin autoimmune urticaria. This process may be complement (C)-dependent and C5a itself is a potent degranulating agent in the laboratory. Fortunately, opiates such as codeine and morphine do not often cause urticaria despite their widespread use in medicine, even though they are standard laboratory nonimmunological degranulating stimuli.

How physical stimuli cause inducible urticarias is unclear but some historical evidence from passive transfer experiments suggests that IgE may be involved. There is evidence that cutaneous mast cells are generally more 'releasable' in chronic spontaneous urticaria to nonimmunological stimulation with compound 48/80. ${ }^{12}$ In contrast, blood basophils are less responsive to the immunological stimulus anti-IgE, the latter recovering as the disease goes into spontaneous remission. ${ }^{13}$

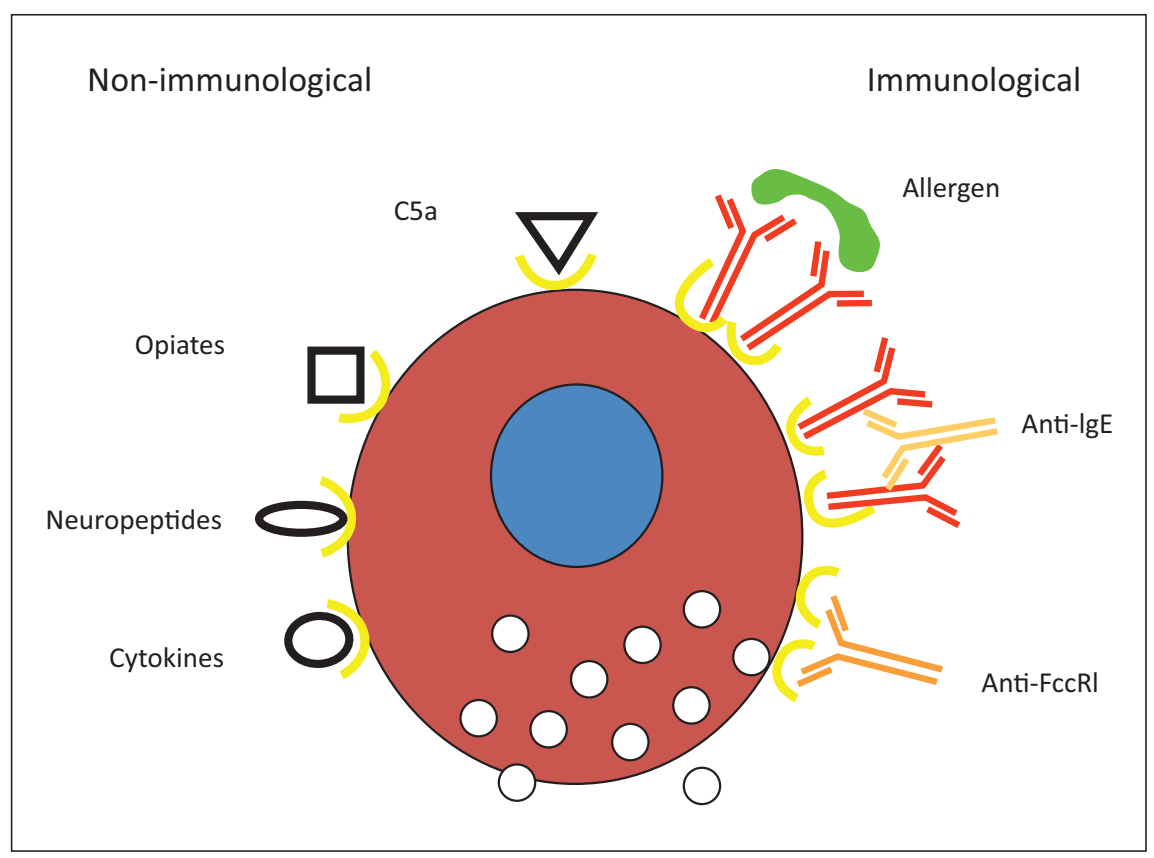

Fig 3. Schematic diagram of non-immunological and immunological mast cell degranulating stimuli. $\mathrm{FccRI}=$ high affinity immunoglobulin (Ig) receptor. 


\section{Angio-oedema without wheals}

Urticaria may present as angio-oedema without wheals in approximately $10 \%$ of patients. ${ }^{1}$ This is an important subgroup since some of these patients will have hereditary angio-oedema. There is increasing recognition that angio-oedema without wheals may be mast cell-dependent or -independent. The latter form is mediated by bradykinin and is usually considered a different disease.

The important message for clinicians is that hereditary angio-oedema and other presentations of mast cell-independent angio-oedema should always be actively confirmed or excluded by appropriate assessment, including requests for $\mathrm{C} 4$ complement and $\mathrm{C} 1$ esterase inhibitor assays on fresh blood samples.

\section{Management}

The management of urticaria is well covered in consensus documents. ${ }^{6,14}$ The basic principles are to identify from the history aggravating factors for chronic spontaneous urticaria that could potentially be minimised or avoided by the patient. These include local heat, clothing pressure, emotional stress, nonsteroidal anti-inflammatory drug intake and dietary pseudoallergens. The symptoms of the disease are treated with $\mathrm{H}_{1}$ antihistamines until spontaneous remission occurs.

Unfortunately, a minority of patients with more severe urticaria require additional measures to control their disease, including higher doses of antihistamines, ${ }^{15}$ second-line targeted treatments including oral corticosteroids or immunosuppressive drugs (eg ciclosporin, ${ }^{16}$ methotrexate ${ }^{17}$ or mycophenolate mofetil ${ }^{18}$ ). Because of the natural history of spontaneous remission in chronic urticaria, it is hard to be sure on the current incomplete evidence whether these are disease-modifying or primarily disease-suppressing therapies. Further study is needed.

Attention has focused recently on omalizumab (a chimeric monoclonal anti-IgE biologic) because of its striking effectiveness in both antihistamineunresponsive spontaneous ${ }^{19}$ and inducible urticarias. ${ }^{20}$ Licensing studies are ongoing.

\section{References}

1 Maurer M, Weller K, Bindslev-Jensen C et al. Unmet clinical needs in chronic spontaneous urticaria. A GA ${ }^{2} \mathrm{LEN}$ task force report. Allergy 2011;66:317-30.

2 O’Donnell BF, Lawlor F, Simpson J et al. The impact of chronic urticaria on the quality of life. Br J Dermatol 1997;136:197-201.

3 Zuberbier T, Asero R, Bindslev-Jensen C et al. EAACI/GA(2)LEN/EDF/WAO guideline: definition, classification and diagnosis of urticaria. Allergy 2009;64:1417-26.

4 Greaves M. Chronic urticaria. Review. J Allergy Clin Immunol 2000;105:664-72.

5 Grattan CE. Autoimmune urticaria. Review. Immunol Allergy Clin North Am 2004;24:163-81.

6 Grattan CE, Humphreys F; British Association of Dermatologists Therapy Guidelines and Audit Subcommittee. Guidelines for evaluation and management of urticaria in adults and children. $\mathrm{Br} \mathrm{J}$ Dermatol 2007;157:1116-23.

7 Ying S, Kikuchi Y, Meng Q et al. TH1/TH2 cytokines and inflammatory cells in skin biopsy specimens from patients with chronic idiopathic urticaria: comparison with the allergen-induced late-phase cutaneous reaction. J Allergy Clin Immunol 2002;109:694-700.

8 Puccetti A, Bason C, Simeoni S et al. In chronic idiopathic urticaria autoantibodies against Fc epsilonRII/CD23 induce histamine via eosinophil activation. Clin Exp Allergy 2005;35:1599-1607.

9 Grattan CE, Francis DM, Hide M, Greaves MW. Detection of circulating histamine releasing autoantibodies with functional properties of anti-IgE in chronic urticaria. Clin Exp Allergy 1991;21:695-704.

10 Hide M, Francis DM, Grattan CE et al. Autoantibodies against the high-affinity IgE receptor as a cause of histamine release in chronic urticaria. N Engl J Med 1993;328:1599-604.

11 Niimi N, Francis DM, Kermani F et al. Dermal mast cell activation by autoantibodies against the high affinity $\operatorname{IgE}$ receptor in chronic urticaria. J Invest Dermatol 1996;106:1001-6.

12 Bédard PM, Brunet C, Pelletier G, Hébert J. Increased compound 48/80 induced local histamine release from nonlesional skin of patients with chronic urticaria. J Allergy Clin Immunol 1986;78:1121-5.

13 Eckman JA, Hamilton RG, Gober LM et al. Basophil phenotypes in chronic idiopathic urticaria in relation to disease activity and autoantibodies. J Invest Dermatol 2008;128:1956-63.

14 Zuberbier T, Asero R, Bindslev-Jensen C et al. EAACI/GA(2)LEN/EDF/WAO guideline: management of urticaria. Allergy 2009;64:1427-43.

15 Staevska M, Popov TA, Kralimarkova T et al. The effectiveness of levocetirizine and desloratadine in up to 4 times conventional doses in difficult-to-treat urticaria. J Allergy Clin Immunol 2010;125:676-82.

16 Grattan CE, O'Donnell BF, Francis DM et al. Randomized double-blind study of cyclosporin in chronic 'idiopathic' urticaria. Br J Dermatol 2000;143:365-72.

17 Perez A, Woods A, Grattan CE. Methotrexate: a useful steroid-sparing agent in recalcitrant chronic urticaria. $\mathrm{Br} \mathrm{J}$ Dermatol 2010;162:191-4.

18 Shahar E, Bergman R, Guttman-Yassky E, Pollack S. Treatment of severe chronic idiopathic urticaria with oral mycophenolate mofetil in patients not responding to antihistamines and/or corticosteroids. Int $J$ Dermatol 2006;45:1224-7.

19 Maurer M, Altrichter S, Bieber T et al. Efficacy and safety of omalizumab in patients with chronic urticaria who exhibit IgE against thyroperoxidase. J Allergy Clin Immunol 2011;128:202-9.

20 Metz M, Altrichter S, Ardelean E et al. Anti-immunoglobulin E treatment of patients with recalcitrant physical urticaria. Int Arch Allergy Immunol 2011;154:177-80.

Address for correspondence: $\mathrm{Dr} C$ Grattan, Norfolk and Norwich University Hospital, Colney, Norwich NR4 7UY. Email: clive.e.grattan@gstt.nhs.uk 